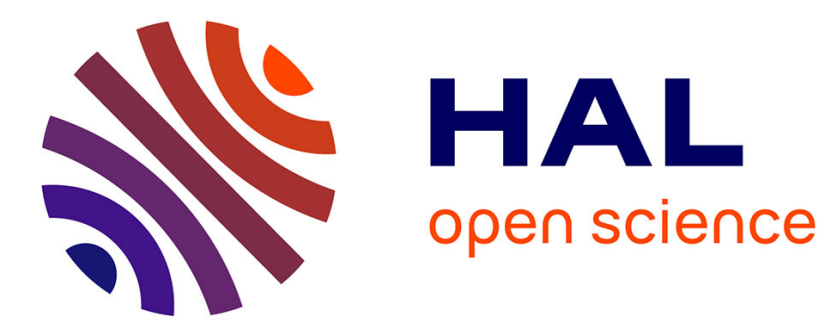

\title{
Determination of absorption characteristic of materials on basis of sound intensity measurement
}

\author{
R. Prascevic, A. Milosevic, S. Cvetkovic
}

\section{To cite this version:}

R. Prascevic, A. Milosevic, S. Cvetkovic. Determination of absorption characteristic of materials on basis of sound intensity measurement. Journal de Physique IV Proceedings, 1994, 04 (C5), pp.C5159-C5-162. 10.1051/.jp4:1994529 . jpa-00253002

\section{HAL Id: jpa-00253002 https://hal.science/jpa-00253002}

Submitted on 1 Jan 1994

HAL is a multi-disciplinary open access archive for the deposit and dissemination of scientific research documents, whether they are published or not. The documents may come from teaching and research institutions in France or abroad, or from public or private research centers.
L'archive ouverte pluridisciplinaire HAL, est destinée au dépôt et à la diffusion de documents scientifiques de niveau recherche, publiés ou non, émanant des établissements d'enseignement et de recherche français ou étrangers, des laboratoires publics ou privés. 


\title{
Determination of absorption characteristic of materials on basis of sound intensity measurement
}

\author{
R.M. PRASCEVIC, A.M. MILOSEVIC* and S.D. CVETKOVIC \\ Faculty of Occupational Safety of Nis, Camojevica 10 a, 18000 Nis, Yugoslavia \\ ${ }^{*}$ Faculty of Electronic Engineering of Nis, Beogradska 14, 18000 Nis, Yugoslavia
}

\begin{abstract}
The coefficient of the acoustic absorption of the materials can be determined using two standard methods: the standing wave method and the reverberation room method. In this paper, starting from the fact that the sound intensity as vector quantity describes, beside the amount of the sound energy its direction as well and that intensity vector distribution on the floor of the rectangular rooms is rather uniform, a procedure of the absorption characteristics determination of the absorber specimen by measuring of the sound intensity is suggested. The comparative results of the absorption coefficient determination of the glass wool, obtained by reverberation room method and suggested procedure, are given. The first results point out to the possibility of the absorbed energy determination in the rectangular parallelepiped rooms, using suggested procedure on the basis of the sound intensity measurement.
\end{abstract}

\section{INTRODUCTION}

The sound absorption characteristics, in particular those of the plane absorbers, are usually determined in the reverberation rooms. Although the essential details of the measuring procedure are regulated by international and national standards $[1,2]$, the deviations in the results obtained in different measuring laboratories appear. The endeavours have been made for a long time to find the reasons for these deviations. As electronics measuring devices, on today's level of development, have attained the precision grade of the order of $0.1 \mathrm{~dB}$, the precision of the measuring devices as well as the man's care during the measuring procedure can be excluded as possible causes. The previous experiences lead us to an obvious conclusion that the deviations steam from the sound field itself to which the specimen is exposed during the measurement [3]. The configuration of the sound field at the specimen surface depends upon the dimension and shape of the measuring rooms, the area and the position of the measuring specimen, the position and the characteristics of the sound source and source receiver, etc.

A prerequisite for the application of the reverberation room method is the presence of a diffuse sound field during the measurement. This condition can only be reached on the ideal model, because in the real situation the room boundaries don't remain ideal reflectors when there is an absorber specimen inside the room. The absorber specimen itself is no longer exposed to the sound field condition which would be expected in the ideally diffuse sound field. The theory has shown that the absorption coefficient can be determined in the room having the shape of a rectangular parallelepiped, if the following requirements are satisfied in order to obtain an approximately diffuse sound field [4]:

- the sound source and the source receiver are omnidirectional,

- the sound source radiates a broad band sound,

- the specimen is equally arranged on the all room boundaries, or at least three ones, 
- the room dimension are in the certain ratio, and etc.

Starting from the fact that the sound intensity as vector quantity describes, besides the amount of the sound energy its direction as well and that intensity vector distribution on the floor of the rectangular rooms is rather uniform [3], in this paper a procedure of the absorption characteristics determination of the absorber specimen by measuring the sound intensity is suggested. The comparative results of the absorption coefficient determination of the glass wool, obtained by reverberation room method and suggested procedure, are given.

\section{SOUND INTENSITY AS A MEASURE OF ENERGY ABSORBED BY MATERIAL}

The absorption coefficient is a measure of absorption power of the certain material, that is defined as the ratio of the sound energy absorbed by a surface $\left(\mathrm{W}_{\mathrm{abs}}\right)$ to the sound energy incident upon that surface $\left(\mathrm{W}_{\mathrm{inc}}\right),[5]$ :

$$
\alpha=\frac{W_{\text {abs }}}{W_{\text {inc }}}=\frac{W_{\text {inc }}-W_{\text {ref }}}{W_{\text {inc }}}
$$

where: $\quad W_{\text {ref }}$ - the sound energy reflected from the surface.

Sound intensity measurements supply an alternative approach to the determination of the absorbed energy by a certain material. As the sound intensity is a vector quantity, it describes beside the amount of the sound energy and its direction passing through the observed surface. The sound intensity is measured by two-microphone sound intensity probe and by appropriate analyzers. The sound intensity probe, which has two pairs of phase-matched microphones, measures the sound intensity component in direction in which it is directed [6,7].

To obtain general idea about the new procedure of the absorption coefficient determination, the measurement surface can be imagined as a surface in space right above the absorber. The incident sound wave passes through that surface, strikes against the measurement specimen, and one part of the sound energy is reflected while the rest is absorbed. The part of the sound energy that is reflected passes again through the imagined surface but in the opposite direction of the incident wave direction, so that the sound intensity probe registers the difference between incident and reflected waves. This difference is the sound energy absorbed by the material specimen. Therefore, the absorbed sound energy can be determined by sound intensity measurement, right above the surface specimen that is attached, or leaned, to the hard base. The imagined surface is divided to the segments and the sound intensity is measured in all segments. In this manner the sound intensity distribution on the measurement surface is obtained . Then, the absorbed sound energy can be determined in accordance with the equation:

$$
\mathrm{W}_{\mathrm{abs}}=\sum_{\mathrm{k}=1}^{\mathrm{m}} \mathrm{I}_{\mathrm{k}} \cdot \Delta \mathrm{S}_{\mathrm{k}}
$$

where: $\quad I_{k} \quad$ - the sound intensity measured on the $k$-th segment

$\Delta S_{k} \quad$ - area of the $k$-th segment

$\mathrm{m} \quad$ - number of the segment

S - area of the measurement specimen.

Assuming that the local changes of the sound intensity for the homogeneous specimen are small and that the measurement surface is divided into $m$ equal segments, the equation (2) becomes:

$$
\mathrm{W}_{\mathrm{abs}}=\overline{\mathrm{I}} \cdot \mathrm{S}
$$

where:

$\overline{\mathrm{I}}$ - the averaged sound intensity at the measurement surface. 
The incident sound energy in diffuse sound field can be determined in accordance with the equation:

$$
\mathrm{W}_{\text {inc }}=\frac{\overline{\mathrm{p}}_{\mathrm{rms}}^{-2} \cdot \mathrm{S}}{4 \mathrm{pc}}
$$

where $: \bar{p}_{\text {rms }}$ - the averaged root mean square sound pressure at the measurement surface.

Replacing equations (3) and (4) in (1), we gets:

$$
\alpha=\frac{\overline{\mathrm{I}} \cdot 4 \rho \mathrm{c}}{\overline{\mathrm{p}}_{\mathrm{rms}}^{2}}
$$

If the sound pressure and the sound intensity are expressed by sound pressure level and sound intensity level, respectively, the equation (5) becomes:

$$
\alpha=\operatorname{anti} \log \left\{\left[\overline{\mathrm{L}}_{\mathrm{I}}-\left(\overline{\mathrm{L}}_{\mathrm{p}}-6\right)\right] / 10\right\}
$$

where: $\quad \bar{L}_{\mathbf{I}}$ - the averaged sound intensity level at the measurement surface

$\overline{\mathrm{L}}_{\mathrm{p}}$ - the averaged sound pressure level at the measurement surface.

\section{MEASUREMENT RESULTS}

The absorption coefficient determination of the examination specimen has been carried out in the rectangular room of relatively large dimensions, $\left(8.9 \times 6.2 \times 3.8 \mathrm{~m}^{3}\right)$. The average time reverberation measured in an empty room falls from $3 \mathrm{~s}$ to $1 \mathrm{~s}$, in frequency octave band from $125 \mathrm{~Hz}$ to $4000 \mathrm{~Hz}$. The measurement specimen of the glass wool, $0.05 \mathrm{~m}$ thick, in the form of the panel of the area of $0.5 \mathrm{~m}^{2} \mathrm{has}$ been placed onto the concrete floor, so that the total measurement area is $1 \mathrm{~m}^{2}$ Larger areas havn't been taken into consideration, so that to the diffuseness of the empty room changes as little as possible. In this way the determined measurement surface, $0.1 \mathrm{~m}$ above specimen, has been divided into 16 segments and on all segments out sound intensity measurements, using Dual Channel Signal Analyzer Type 2032 B\&K with Sound Intensity Probe Type 3519 B\&K, have been carried. All measurements have been carried out with a microphone spacing of $\Delta \mathrm{r}=12 \mathrm{~mm}$, in octave bands from $125 \mathrm{~Hz}$ to $500 \mathrm{~Hz}$, and with $\Delta \mathrm{r}=50 \mathrm{~mm}$ in the octave bands from $1000 \mathrm{~Hz}$ to $4000 \mathrm{~Hz}$. The sound pressure level has been measured at the same points as the sound intensity level, but in the empty rooms without the specimen. For these measurements, Dual Channel Real Time Frequency Analyzer Type 2144 B\&K with Condenser Microphone Type 4465 B\&K have been used.

The averaged values of the measured sound pressure level and sound intensity level, as well as the calculated value of the absorption coefficient of the examination specimen, in accordance with the equation (6), are shown in Table I. The frequency characteristic of the calculated absorption coefficient of the examination specimen is plotted on the Fig. 1. In order to make a comparative analysis of the obtained results. on the same figure, the frequency characteristic of the absorption coefficient of the same specimen obtained in the reverberation room, volume $239 \mathrm{~m}^{3}$, in accordance DIN 52212 [4], is plotted.

Table I The absorption coefficient of the glass wool calculated in accordance with the equation (6)

\begin{tabular}{|l|c|c|c|c|c|c|}
\hline $\mathrm{f}[\mathrm{Hz}]$ & 125 & 250 & 500 & 1000 & 2000 & 4000 \\
\hline $\mathrm{L}_{\mathrm{I}}[\mathrm{dB}]$ & 75.2 & 82.8 & 89.6 & 85.7 & 84.4 & 79.6 \\
\hline $\mathrm{L}_{\mathrm{p}}[\mathrm{dB}]$ & 91.6 & 94.1 & 97.8 & 92.8 & 91.4 & 87.0 \\
\hline$\alpha[\%]$ & 9.1 & 29.5 & 60.2 & 77.6 & 79.4 & 72.4 \\
\hline
\end{tabular}




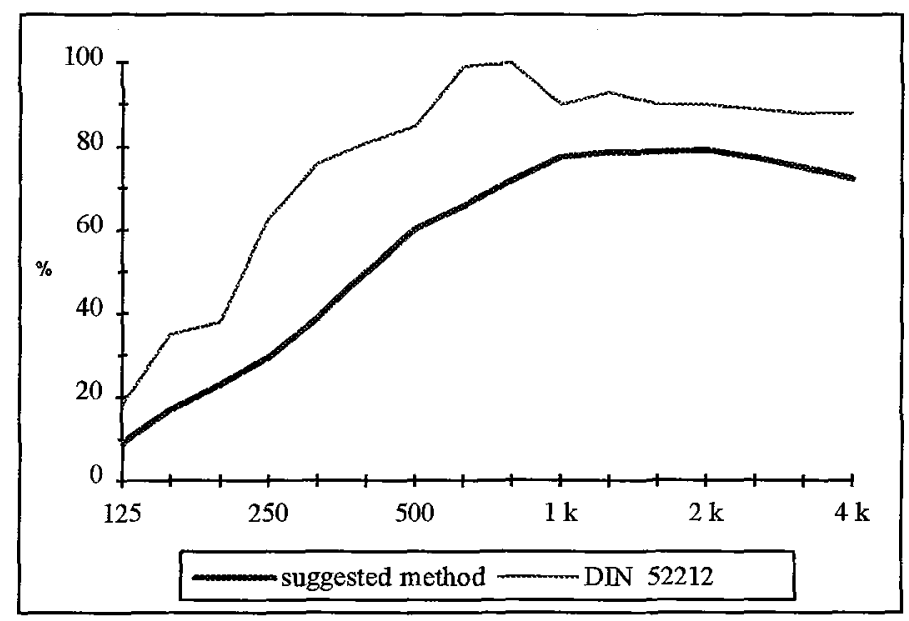

Fig. 1 Frequency characteristics of the absorption coefficient of the glass wool

\section{DISCUSSION AND CONCLUSION}

In spite of the similar shape of the plotted characteristics in Fig. 1, there are the certain differences. These differences could have been expected because these are the initial results of the practical work in the new procedure examination of the absorption coefficient determination. This procedure can certainly be improved. For example:

- In spite of the uniform distribution of the sound intensity at the measurement surface, the deviations appear, so that the intensity vector is not always perpendicular to the measurement surface. By measuring of the normal component of the sound intensity, the error is made, that can be avoided by measuring the sound intensity in three perpendicular directions, obtaining real value of the intensity vector.

- In order to avoid the edge effect in the measurement, the measurement specimen should be larger, so that the measurement points have are not at near the measurement specimen edges.

- Performer of the measurement should not be in the room.

The first results point out to the possibility of the absorbed energy determination in the rectangular parallelepiped room, using the suggested procedure on the basis of the sound intensity measurement. The target of our future work is a development and impovement of the suggested procedure.

\section{REFERENCE}

[1] ISO 354-1985, Acoustics Measurements of Sound Absorption in a Reverberation Room

[2] JUS U.J6.059, Measurements of Sound Absorption Coefficient in a Reverberation Room

[3] P. Damming, Model Investigations into Sound Fields in Reverberation Rooms, Acustica, Vol.75 pp. $105-120,1991$

[4] M.A.Milosevic, The Evaluation of the Sound Absorption Coefficient in the Rectangular Rooms, XIX Yugoslav Conference ETAN, pp. 735-743, (in Serbian), Ohrid 1975

[5] L.L. Beranek, Acoustics, McGraw Hill Book Company Inc., 1977

[6] Gade, Sound Intensity (Part I), Technical Review No.3, Bruel\&Kjaer, 1982

[7] Gade, Sound Intensity (Part II), Technical Review No.4, Bruel\&Kjaer, 1982 